\title{
Potential evapotranspiration trends in West Africa from 1906 to 2015
}

\author{
Olawale E. Abiye ${ }^{1}$. Olaniran J. Matthew ${ }^{2} \cdot$ Lukman A. Sunmonu $^{3} \cdot$ Oladimeji A. Babatunde $^{3}$ \\ (c) Springer Nature Switzerland AG 2019
}

\begin{abstract}
In this study, Climate Research Unit monthly observations were used to assess the trends of potential evapotranspiration (PET) over West Africa from 1906 to 2015. Trends and changes in PET during the 110-year study period and two reference climatological periods (1931-1960 and 1961-1990) were examined. Nonparametric trend test of the Mann-Kendall and Kolmogorov-Smirnov was employed to find the changes in trends of PET and their significance or otherwise. The contributions of some meteorological parameters (air temperatures, precipitation and cloud cover) to the observed trends in PET were also examined. Results of long-term data analysis showed mixed trends in PET in the three designated zones (Guinea, Savanna and Sahel) but notable significant increasing trends $(0.165 \mathrm{~mm}$ per year) at $p=0.1$ in Sahel. However, very sharp differences in PET were observed in both reference periods across the zones with significant decreasing trends (at $p=0.01$ ) in PET during the first period but increasing significant trends (at $p=0.1$ ) during the second. In spite of this pattern of variations, general reductions in PET $(-0.6 \%$ to $-1.2 \%)$ were observed, which were found to be triggered by decrease in temperature $(-0.13$ to $-1.07 \%)$ and vapour pressure $(-0.02$ to $-0.33 \%)$ as well as increase in cloudiness (0.01-0.05\%). However, the magnitudes of changes in PET were found to be insignificant in all the zones. Maximum temperature, more than other dominant climatic parameters, contributed significantly (Theil-Sen's regression: $23.5 \% \leq \beta \leq 50.3 \% ; p=0.01$ ) to observed variations in PET.
\end{abstract}

Keywords PET·Trends · West Africa · Guinea · Savanna · Sahel

\section{Introduction}

In hydrology, and in studies relating to water availability for crops, both free surface evaporation and potential evapotranspiration play important roles [1, 2]. Potential evapotranspiration (PET) is the combined evaporation from the soil surface and transpiration from plants when the water supply is unlimited [3]. It is the maximum quantity of water capable of being lost as water vapour, under a given climate, by a continuous, extensive stretch of vegetation covering the ground when there is no shortage of water [4-6]. Previous studies have established that accurate measurement or estimation of PET is very useful for the determination of onset of rainfall, particularly in the arid or Sudan-Sahel region of West Africa [7]. Therefore, measurement and study of changes in PET are of great significance because of their relevance to agriculture [8].

PET is influenced by several factors amongst which include net (solar) radiation, relative humidity, air temperatures, wind speed, atmospheric aerosol (including dust particles), type and size of vegetative cover, availability of soil moisture, reflective land surface, and change in land use/land cover [9-11]. Thus, any changes in these variables due to climate change are likely to change the value of PET that have a direct impact on precipitation and hydrological regimes as well as crop production through changes in the agro-ecological water balance [12-15].

To this effect, several authors have investigated variations in PET at spatial and temporal scales over different regions of the world due to the impacts of global warming

Olaniran J. Matthew, abefematt@yahoo.com $\mid{ }^{1}$ Centre for Energy Research and Development, Obafemi Awolowo University, Ile-Ife, Nigeria. ${ }^{2}$ Institute of Ecology and Environmental Studies, Obafemi Awolowo University, Ile-Ife, Nigeria. ${ }^{3}$ Department of Physics and Engineering Physics, Obafemi Awolowo University, Ile-Ife, Nigeria.

SN Applied Sciences (2019) 1:1434 | https://doi.org/10.1007/s42452-019-1456-6

Received: 8 July 2019 / Accepted: 3 October 2019 / Published online: 17 October 2019 
$[14,16-19]$. It was reported that global warming would lead to a possible intensification of the hydrological cycle resulting from increase in precipitation and PET $[20,21]$. However, there were mixed results on the trends of recent and future PET over different parts of the world. Some of them had pointed out upward trends in PET time-series analysis. These include the works of Gao et al. [22] and Liu et al. [15] over China regions; Chaouche et al. [23] in France; Kousari et al. [24], Tabari et al. [25] and Talaee et al. [26] in Iran; Jhajharia et al. [14] in India; Dinpashoh et al. [27] in north-west Iran; Onyutha [28] in Nile River and Ashaolu and Iroye [10] in western Nigeria. Others reported downward trends or both, e.g. Chattopdhyay and Hulme [1] and Darshana et al. [29] in India; Chen et al. [30] in Central and East Asia (Tibetan Plateau); Gao et al. [22] and Yin et al. [31] in China; Irmak et al. [32] in America; Obada et al. [6] and Hounnou and Dedehouanou [2] in Benin, West Africa.

Furthermore, PET is projected to increase in coming years over some regions of the world (e.g. India [33]; China [19], etc.) and decrease in some others, e.g. China [31, 34, 35], Korea [36] and the USA [37]. Therefore, global atmospheric temperature rise could result in both a rise and decline in PET over different regions. For example, a decrease in solar radiation, rainfall or wind speed could compensate for the impact of temperatures on PET, which has been observed in many places $[36,37]$. Generally, causes of recent or future PET changes varied at different stations and seasons [19]. However, significant increases in PET over different parts of the world have been attributed to increase in air temperature and wind speed as well as decrease in humidity [38-41], while decrease in PET was due to increase in relative humidity and decrease in net radiation, vapour pressure and wind speed $[1,42,43]$.

Thus, increased evapotranspiration can be translated to increase in atmospheric water demand with a very high efficiency over vegetation (under optimal growing conditions) and free water surfaces [44]. Consequently, better understanding of spatiotemporal patterns of PET and regional response of PET to climate change can contribute to the establishment of a policy to realize a more efficient use of water resources and a sustainable agricultural production [15], particularly in the West African region where the basis of almost all life is agricultural pursuits [45].

However, the impacts of climate change on the PET at short, medium and long term are not yet fully explored in West Africa $[2,6]$. This research, therefore, investigates changes in trends of long-term series (1906-2015) of observed PET over West Africa. It assesses changes in climatic parameters for the 1931-1960 and 1961-1990 reference periods in order to find out which period has PET deficit and the dominant climatic factors affecting PET in the region.

\section{Materials and methods}

\subsection{Study area}

The domain of this study is West Africa $\left(18^{\circ} \mathrm{W}-15^{\circ} \mathrm{E}\right.$, $4^{\circ}-24^{\circ} \mathrm{N}$ ) subcontinent (Fig. 1) with a special focus on three designated zones, i.e. Guinea $\left(4^{\circ} \mathrm{N}-8^{\circ} \mathrm{N}\right)$, Savanna $\left(8^{\circ}-11^{\circ} \mathrm{N}\right)$ and Sahel $\left(11^{\circ}-16^{\circ} \mathrm{N}\right)$ as previously adopted in Omotosho and Abiodun [46] and Abiodun et al. [47].

\subsection{Data source}

Monthly time-series gridded data of PET from 1906 to 2015, provided by the Climate Impacts LINK project, University of East Anglia, Norwich, United Kingdom Climate Research Unit (CRU) (version TS 4.00) of spatial resolution of $0.5^{\circ} \times 0.5^{\circ}$ [48], were used. Data on air temperatures, cloud cover and
Fig. 1 West African Domain and the regions designated as Guinea, Savanna and Sahel zones in this study. Adapted after Abiodun et al. [65])

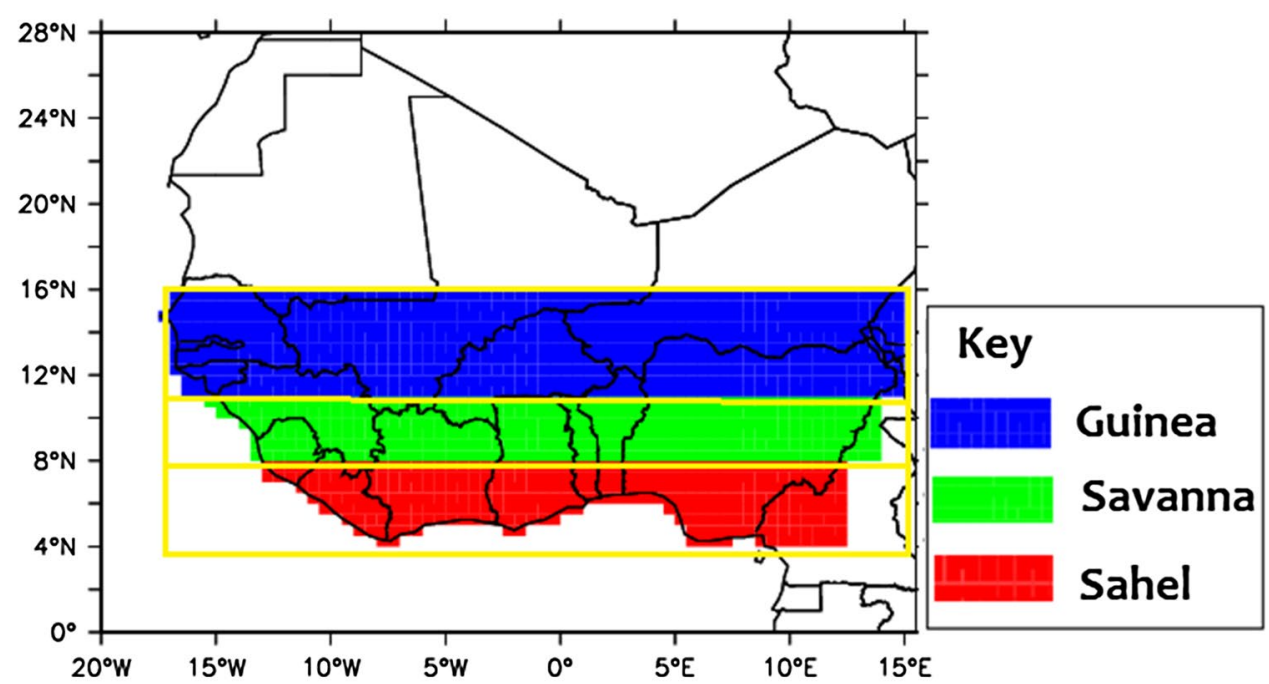


precipitation used in this study to examine the possible causes of variations in PET were also provided in the CRUTS v4.00 product. The CRU data estimates were based on the Global Gridded Climatology data [49, 50].

\subsection{Data analyses and procedures}

The trends in PET were detected by using the Mann-Kendall $(M-K)$ test after the removal of the significant lag-1 serial correlation effect from all the PET time series by pre-whitening. The $\mathrm{M}-\mathrm{K}$ test is a nonparametric trend test which is often used to test for trends in hydro-climatological time series [51-54]. In addition, another relevant and robust nonparametric test of Kolmogorov-Smirnov was applied to further confirm the significance or otherwise of the trends of probability distribution curves of the PET for the two reference periods.

The trend analyses were carried out over the entire 110-year study period and also for the 1931-1960 and 1961-1990 reference periods designated by the World Meteorological Organization (WMO) for climatologic studies $[55,56]$. Annual and seasonal changes in PET during the two reference periods were investigated.

Furthermore, the Theil-Sen's regression method [11, $54,57,58]$ was performed on time series of some meteorological parameters (air temperatures, precipitation and cloud cover) as independent variables to estimate the relationships among variables and their contributions to the observed trends in PET as a dependent variable [40]. The variability in the mean climatology during the two reference periods was investigated using standardized or normalized anomaly, and ND is defined as:

$\mathrm{ND}=\frac{(X-\bar{X})}{\sigma}$

where $X$ is the data annual value, $\bar{X}$ is the data annual mean of the baseline period (1931-1960) and $\sigma$ is the climatological standard deviation. ND generally provides more information about the magnitude of the anomaly because influences of dispersion have been removed.

\subsubsection{Mann-Kendall test}

The Mann-Kendall ( $\mathrm{M}-\mathrm{K}$ ) test is applicable in cases when the data values $X_{i}$ of a time series can be assumed to obey the model $[59,60]$ :

$X_{i}=f\left(t_{i}\right)+\varepsilon_{i}$

where $f\left(t_{i}\right)$ is a continuous monotonic increasing or decreasing function of $t$, and the residual $\varepsilon_{i}$ can be assumed to be from the same distribution with zero mean. The $M-K$ test statistic $S$ is given as:
$S=\sum_{k=1}^{n-1} \sum_{j=k+1}^{n} \operatorname{sgn}\left(X_{j}-X_{k}\right)$

where $n$ is the length of the time series $X_{i}, \ldots, X_{n}, \operatorname{sgn}($.$) is$ a sign function, $X_{j}$ and $X_{k}$ are the values in years $j$ and $k$, respectively. The sign function can be computed as:

$\operatorname{sgn}\left(X_{j}-X_{k}\right)=\left\{\begin{array}{lll}1 & \text { if } & \left(X_{j}-X_{k}\right)>0 \\ 0 & \text { if } & \left(X_{j}-X_{k}\right)=0 \\ -1 & \text { if } & \left(X_{j}-X_{k}\right)<0\end{array}\right.$

The expected value of $S$ equals zero $[E(S)=0]$ for series without trend, and the variance, $\sigma^{2}(S)$, is computed as:

$\sigma^{2}(S)=\frac{1}{18}\left[n(n-1)(2 n+5)-\sum_{p=1}^{q}\left(t_{p}-1\right)\left(2 t_{p}+5\right)\right]$

where $q$ is the number of tied groups and $t_{p}$ is the number of data values in $p$ th group. The test statistic $Z$ is then given as:

$Z= \begin{cases}\frac{S-1}{\sqrt{\sigma^{2}(S)}} & \text { if } S>0 \\ 0 & \text { if } S=0 \\ \frac{S+1}{\sqrt{\sigma^{2}(S)}} & \text { if } S<0\end{cases}$

If $-Z_{1-\frac{\alpha}{2}} \leq Z \leq+Z_{1-\frac{\alpha}{2}}$, then the null hypothesis of no trend was accepted at the significance level of $\alpha=0.10,0.05$ and 0.01 . Otherwise, the null hypothesis was rejected and the alternative hypothesis was accepted at the significance level of $a$.

\subsubsection{Theil-Sen's estimator}

The Theil-Sen's estimator, used to estimate the magnitude of a trend, which has been widely used in identifying the slope of the trend line in hydrological time series [61], is given by the relation $[62,63]$ :

$\beta=\operatorname{median}\left(\frac{X_{j}-X_{I}}{j-I}\right) \quad \forall 1<I<j$.

\subsubsection{Trend-free pre-whitening}

The PET data for different zones of West Africa were corrected for lag-1 serial correlation $\left(r_{1}\right)$ by estimating the monotonic trend $(\beta)$ for the series, removing this trend prior to pre-whitening and finally adding the trend to the pre-whitened data series before applying the $\mathrm{M}-\mathrm{K}$ test as recommended by the literature [58]. This approach helps 
to eliminate or minimize possible source of uncertainty that could be associated with significant positive serial correlation on the power of $\mathrm{M}-\mathrm{K}$. The $\mathrm{M}-\mathrm{K}$ test was then used to detect trend in the final (or pre-whitened) series. This procedure can easily be represented as [54]:

$Z_{i}=X_{i}-(\beta \times i)$

where $\beta$ is Sen's estimator. The value of $r_{1}$ of the new time series is first computed and later used to determine the residual series as:

$v_{i}=Z_{i}-r_{1} \times Z_{i-1}$

If the expected value of $r_{1}$ of a trend-free (detrended) series is significantly different from zero at a selected significance level, then the serial independence assumption is rejected and the pre-whitening procedure is performed. Then, the value of $(\beta \times i)$ is added again to the residual data set of Eq. (9) to obtain final (or pre-whitened), $y_{i}$ series as:

$y_{i}=v_{i}+(\beta \times i)$.

\subsubsection{Kolmogorov-Smirnov distribution test}

Both the $\mathrm{M}-\mathrm{K}$ test and the Kolmogorov-Smirnov (K-S) distribution test are nonparametric methods. They are widely applied for detecting a shift (and its significance) in the probability distribution of time-series data over two different periods [64]. The value of the test statistic for the two-sided two-sample $\mathrm{K}-\mathrm{S}$ test is given as [65, 66]:

$T=\operatorname{Sup}_{s}\left|F_{1}(x)-F_{2}(x)\right|$

where $F_{1}$ and $F_{2}$ are the empirical distribution functions based on the two samples of sizes $n_{1}$ and $n_{2}$. The asymptotic $P$ value for this statistic as $n_{1}, n_{2} \rightarrow \infty ; n_{1} \geq n_{2}$ is given by [65]:

$P=Q\left(T \sqrt{\frac{n_{1} n_{2}}{n_{1}+n_{2}}}\right)$

where

$Q(z)=2 \sum_{k=1}^{\infty}(-1)^{k-1} e^{-2 k^{2} z^{2}}$

Because the above series converges rapidly, $Q(z)$ can be approximated using Greenwella and Finchb [67] approximation:

$Q(z) \approx 2 e^{-2 z^{2}}$.

or for even greater accuracy, using

$Q(z) \approx 2\left(e^{-2 z^{2}}-e^{8 z^{2}}\right)$
A more general algorithm of $Q(z)$ for any two sample sizes and tables for various values of $n_{1}$ and $n_{2}$ has been developed by Kim [65] and available in Kim and Jennrich [68].

\section{Results}

\subsection{Long-term mean annual and seasonal variations}

Long-term (1906-2015) annual mean of spatial pattern of CRU-PET in West Africa is presented in Fig. 2. Results showed that PET increased with increasing latitude, i.e. increased northward from the coast. The coasts of Guinea, Sierra Leone, Liberia, and Nigeria recorded the least amount of PET per year (ranging from 1000 to about $1200 \mathrm{~mm}$ ). The annual PET was a little higher (1500 to a little less than $2000 \mathrm{~mm}$ ) further inland into the Savanna area of the subcontinent. The highest PET (about $2400 \mathrm{~mm}$ year ${ }^{-1}$ ) was recorded in the far northern parts (Sahel) of the region, particularly in Mali and Niger in the north-eastern parts. Figure 3 illustrates the minimum and maximum annual values as well as estimated variance and standard deviations. The minimum and maximum were about 1000 and $1400 \mathrm{~mm}_{\text {year }}{ }^{-1}$, respectively, in the coasts. The corresponding values were 1600 and $2000 \mathrm{~mm}_{\text {year }}{ }^{-1}$ in the Savanna zone and 2000 and $2800 \mathrm{~mm}$ year $^{-1}$ in the Sahel. The variance ranged between $480 \mathrm{~mm}$ in the coast and about $1600 \mathrm{~mm}$ in the Sahel and standard deviation between 10 and $45 \mathrm{~mm}$ (Fig. 3b, d).

However, total precipitation, cloud cover and vapour pressure generally decreased northward from the coast. The long-term (LT) annual mean precipitation varied from $1784 \mathrm{~mm}$ in Guinea to $1362 \mathrm{~mm}$ in the Savanna

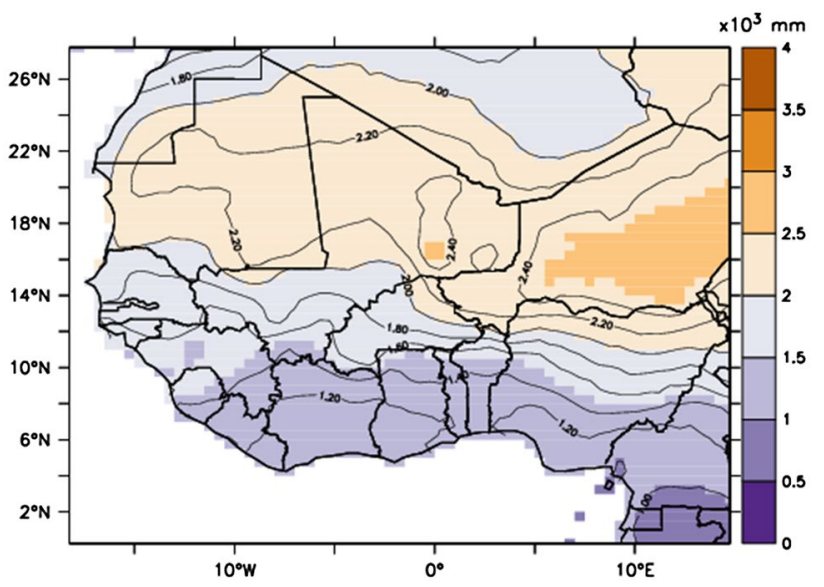

Fig. 2 Spatial pattern of annual mean potential evapotranspiration over West Africa from 1906 to 2015 

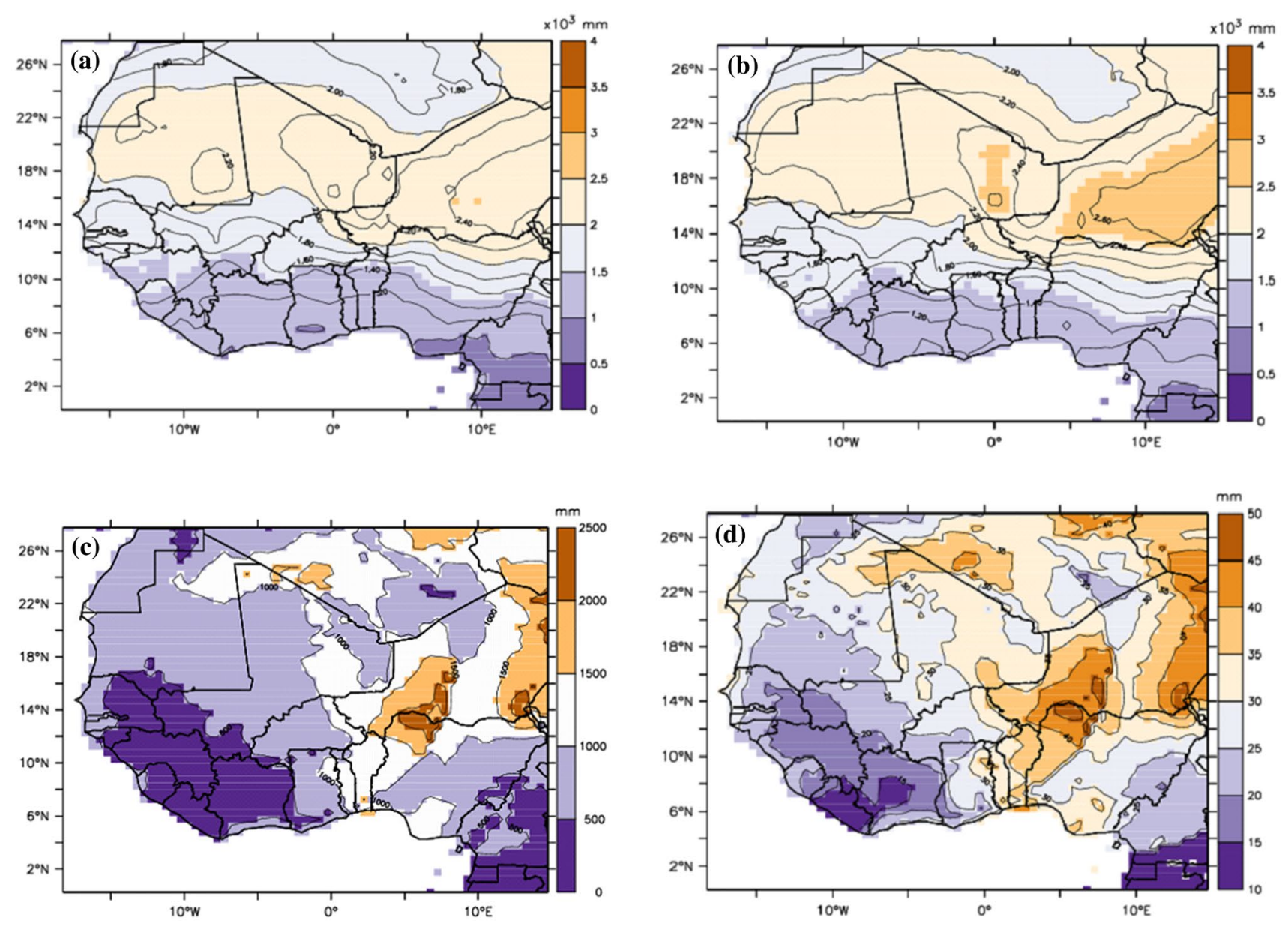

Fig. 3 Spatial pattern of annual statistics of potential evapotranspiration over West Africa from 1906 to 2015: a minimum, b maximum, c variance and $\mathbf{d}$ standard deviation

and $693 \mathrm{~mm}$ in the Sahel (Table 1). In a similar manner, atmospheric vapour pressure decreased from $25.8 \mathrm{hpa}$ in Guinea to $21.5 \mathrm{hpa}$ (Savanna) and $17.4 \mathrm{hpa}$ in Sahel. Values of the cloud cover were 80,65 and $30 \%$ over Guinea, Savanna and Sahel zones, respectively. As rainfall decreases, from south to north, mean temperature increases northward from Guinea $\left(26^{\circ} \mathrm{C}\right)$ to Sahel $\left(28^{\circ} \mathrm{C}\right)$. Observed LT minimum/maximum temperatures were $21.4^{\circ} / 31.0^{\circ} \mathrm{C}$ in Guinea, $20.7^{\circ} / 32.7^{\circ} \mathrm{C}$ in Savanna and $21.1^{\circ} / 35.3^{\circ} \mathrm{C}$ in Sahel.

Figure 4 depicts monthly variations in precipitation and PET across the designated zones. The condition of wet season represents excess precipitation over evapotranspiration (i.e. moisture surplus), while dry season (i.e. water deficit) is represented by the condition of excess evapotranspiration over precipitation $[10,69]$. Thus, results indicated 7 months of water surplus or wet season (April-October) and 5 months of water deficit or dry season (November-March) in Guinea (Fig. 4a). The period of wet season lasted for 6 months (May-October) in Savanna (Fig. 4b) but only 3 months (July-September) in Sahel (Fig. 4c).

\subsection{Long-term interannual variability and trends}

The interannual variability and annual mean trends of PET during the 110-year study period across different zones are represented in Fig. 5. Interannual variabilities were higher ( 2.2 to $-4.3 \mathrm{~mm}$ ) in Savanna than in other zones. The results also demonstrated increasing trends in PET over Sahel and Savanna but a decreasing trend over Guinea. Table 2 presents the magnitude of trends in annual PET time series and other meteorological parameters at different periods across the zones. The positive values of $\beta$ (the Sen's slope) indicate the upward trend line, whereas the negative values show the downward trend at three specific significance levels of $0.01,0.05$ and 0.10 . Similarly, positive values of $Z$ indicate increasing monotonic trends, while negative values show decreasing trends. Specifically, the magnitude of trends in long-term PET was about -0.017 , 
Table 1 Mean, standard deviation and changes in potential evapotranspiration and other meteorological parameters in different zones of West Africa

\begin{tabular}{|c|c|c|c|c|c|c|c|c|c|}
\hline \multirow[t]{3}{*}{ Parameter } & \multirow[t]{3}{*}{ Zone } & \multirow{2}{*}{\multicolumn{2}{|c|}{$\frac{\text { Long-term period }}{1906-2015}$}} & \multirow{2}{*}{\multicolumn{2}{|c|}{$\frac{\text { Period } 1}{1931-1960}$}} & \multirow{2}{*}{\multicolumn{2}{|c|}{$\frac{\text { Period } 2}{1960-1990}$}} & \multirow{2}{*}{\multicolumn{2}{|c|}{$\frac{\text { Changes }}{\text { Periods } 1 \text { and } 2}$}} \\
\hline & & & & & & & & & \\
\hline & & $\overline{\mathbf{x}}$ & $\sigma$ & $\overline{\mathbf{x}}$ & $\sigma$ & $\overline{\mathbf{x}}$ & $\sigma$ & $\Delta$ & $\% \Delta$ \\
\hline \multirow[t]{3}{*}{ PET } & Guinea & 1171.7 & 18.327 & 1179.9 & 18.349 & 1166.3 & 19.111 & -13.54 & -1.15 \\
\hline & Savanna & 1495.7 & 19.008 & 1503.6 & 13.267 & 1489.9 & 19.675 & -13.74 & -0.91 \\
\hline & Sahel & 2013.4 & 22.573 & 2018.2 & 17.906 & 2006.2 & 19.667 & -11.95 & -0.59 \\
\hline \multirow[t]{3}{*}{ PREC } & Guinea & 1784.4 & 150.311 & 1831.7 & 153.140 & 1753.2 & 171.713 & -78.53 & -4.29 \\
\hline & Savanna & 1361.9 & 110.030 & 1404.5 & 95.652 & 1317.0 & 118.103 & -87.50 & -6.23 \\
\hline & Sahel & 693.1 & 93.636 & 757.8 & 76.647 & 642.2 & 95.456 & $-115.5^{*}$ & -15.23 \\
\hline \multirow[t]{3}{*}{ TMIN } & Guinea & 21.4 & 0.384 & 21.4 & 0.344 & 21.3 & 0.346 & -0.11 & -0.53 \\
\hline & Savanna & 20.7 & 0.426 & 20.7 & 0.391 & 20.7 & 0.365 & -0.03 & -0.13 \\
\hline & Sahel & 21.1 & 0.519 & 21.0 & 0.463 & 21.1 & 0.453 & 0.07 & 0.32 \\
\hline \multirow[t]{3}{*}{ TMAX } & Guinea & 31.0 & 0.370 & 31.1 & 0.401 & 30.8 & 0.359 & -0.32 & -1.01 \\
\hline & Savanna & 32.7 & 0.420 & 32.9 & 0.396 & 32.5 & 0.363 & -0.35 & -1.07 \\
\hline & Sahel & 35.3 & 0.477 & 35.3 & 0.433 & 35.1 & 0.389 & -0.26 & -0.74 \\
\hline \multirow[t]{3}{*}{ TMN } & Guinea & 26.2 & 0.360 & 26.2 & 0.362 & 26.0 & 0.340 & -0.21 & -0.82 \\
\hline & Savanna & 26.7 & 0.398 & 26.8 & 0.371 & 26.6 & 0.343 & -0.19 & -0.71 \\
\hline & Sahel & 28.2 & 0.465 & 28.2 & 0.419 & 28.1 & 0.374 & -0.10 & -0.35 \\
\hline \multirow[t]{3}{*}{ CLD } & Guinea & 76.1 & 0.646 & 76.2 & 0.008 & 76.2 & 0.813 & 0.01 & 0.01 \\
\hline & Savanna & 62.9 & 0.790 & 63.0 & 0.027 & 63.0 & 0.696 & 0.01 & 0.02 \\
\hline & Sahel & 39.8 & 0.965 & 39.8 & 0.031 & 39.8 & 0.711 & 0.02 & 0.05 \\
\hline \multirow[t]{3}{*}{ VAP } & Guinea & 25.8 & 0.514 & 25.7 & 0.361 & 25.6 & 0.462 & -0.08 & -0.30 \\
\hline & Savanna & 21.5 & 0.554 & 21.4 & 0.501 & 21.3 & 0.442 & -0.07 & -0.33 \\
\hline & Sahel & 17.4 & 0.533 & 17.3 & 0.505 & 17.3 & 0.388 & -0.003 & -0.02 \\
\hline
\end{tabular}

PET, potential evapotranspiration (mm); PREC, precipitation (mm); TMIN, minimum air temperature $\left({ }^{\circ} \mathrm{C}\right) ; \mathrm{MAX}$, maximum temperature $\left({ }^{\circ} \mathrm{C}\right)$; $\mathrm{TMN}$, mean temperature $\left({ }^{\circ} \mathrm{C}\right) ; \mathrm{CLD}$, cloud cover (\%); VAP, vapour pressure (hpa); $\overline{\mathbf{x}}$, mean value; $\sigma$, standard deviation; $\Delta$, change; $\% \Delta$, percentage change

*Significant changes

0.066 and $0.165 \mathrm{~mm}$ per year over Guinea, Savanna and Sahel, respectively (Table 2). The trend over Sahel was found to be significant at $p=0.1$. During this period, precipitation was found to decrease significantly (at $p=0.05$ ) by about $0.94 \mathrm{~mm}$ per year in Sahel and $-1.3 \mathrm{~mm}$ per year in both Guinea and Savanna zones. In similar manner, cloud cover decreased significantly ( -0.0035 per year) over Guinea. The observed trends in long-term time series of cloud cover were, however, insignificant over Savanna $(-0.0008$ per year) and Sahel (+ 0.0008 per year). Furthermore, both temperatures and vapour pressure increased significantly (at $p=0.05$ ) over the entire region.

\subsection{Changes and trends during 1931-1960 and 1961-1990 WMO reference periods}

Figure 6 shows the trend of PET for the two WMO reference periods across different zones of West Africa. The magnitudes of trends at different significant levels are presented in Table 2. The PET was observed to decrease significantly at $p=0.05$ by 1.41 (Guinea), 0.83 (Savanna) and $1.29 \mathrm{~mm}$ per year (Sahel) between 1931 and 1960. It, however, increased (at insignificant level) by 0.60 (Guinea), 0.61 (Savanna) and $0.40 \mathrm{~mm}$ per year (Sahel) between 1961 and 1990. Precipitation, however, showed increasing trends (1.5-1.9 mm per year) between 1931 and 1960 but decreasing significant trends (7.5-10.6 mm per year) between 1961 and 1990 over the entire West African region (Table 2). Temperatures significantly decreased by $0.021-0.033^{\circ} \mathrm{C}$ per year but increased by $0.008-0.037^{\circ} \mathrm{C}$ per year during the 1931-1960 and 1961-1990 periods, respectively (Table 2). Similarly, trends of vapour pressure and cloud cover decreased during the first period but increased during the second. These trends were significant only in Sahel zone.

Spatial changes in annual PET during 1961-1990 relative to 1931-1960 baseline period are illustrated in Fig. 7. These results showed both negative and positive changes in PET over West Africa. The changes were positive $(\sim 10 \mathrm{~mm}$ or $1 \%)$ in most parts of Senegal, Mauritania 


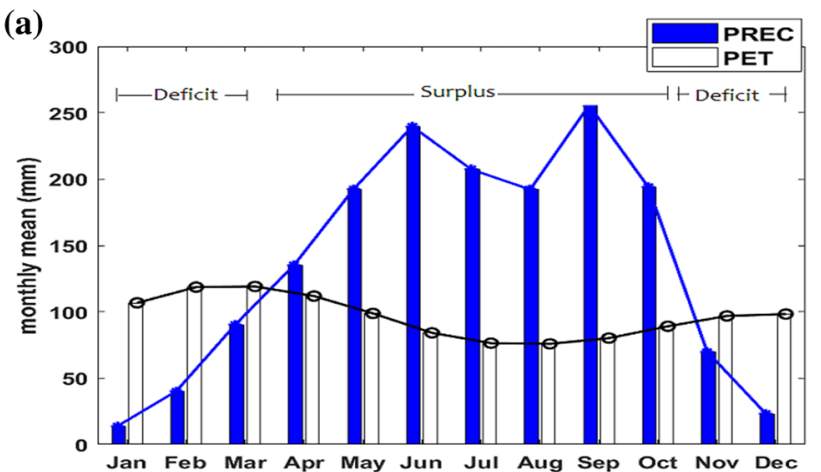

(b)

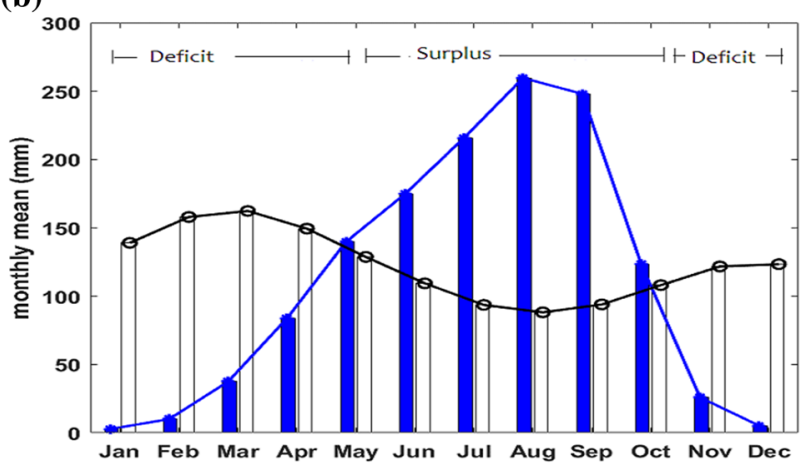

(c)

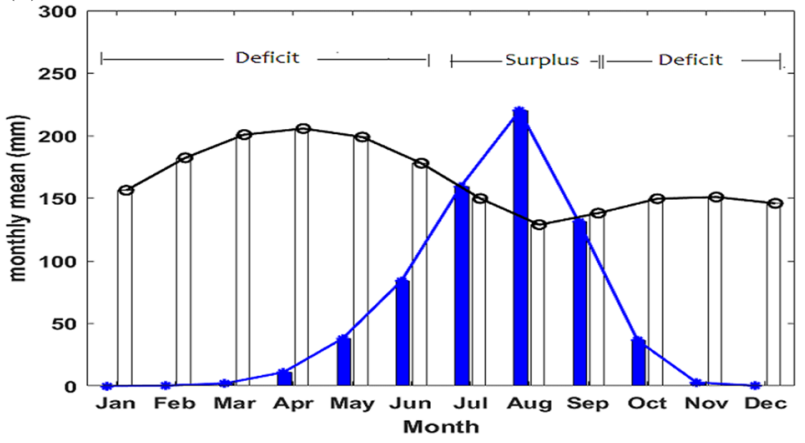

Fig. 4 Monthly mean potential evapotranspiration (PET) and precipitation (PREC) from 1906 to 2015 in different zones of West Africa: a Guinea, b Savanna and c Sahel

and parts of Liberia and Sierra Leone. Other parts of the subcontinent recorded negative $(-10$ to $-22 \mathrm{~mm}$ or 1 to $-2 \%$ ) changes in annual PET. Generally, the changes during the second period were negative over the different zones. The estimated changes in annual PET were $-13.54 \mathrm{~mm}$ or $-1.15 \%$ in Guinea, $-13.74 \mathrm{~mm}$ or $-0.91 \%$ in Savanna and $-11.95 \mathrm{~mm}$ or $-0.595 \%$ in Sahel (Table 1). These changes were found to be insignificant at all the three levels of significance.

Cumulative distribution function (CDF) curves of potential evapotranspiration for different periods and zones of West Africa are illustrated in Fig. 8. A forward (or upward) shift in 1961-1990 CDF curve was noted over the three
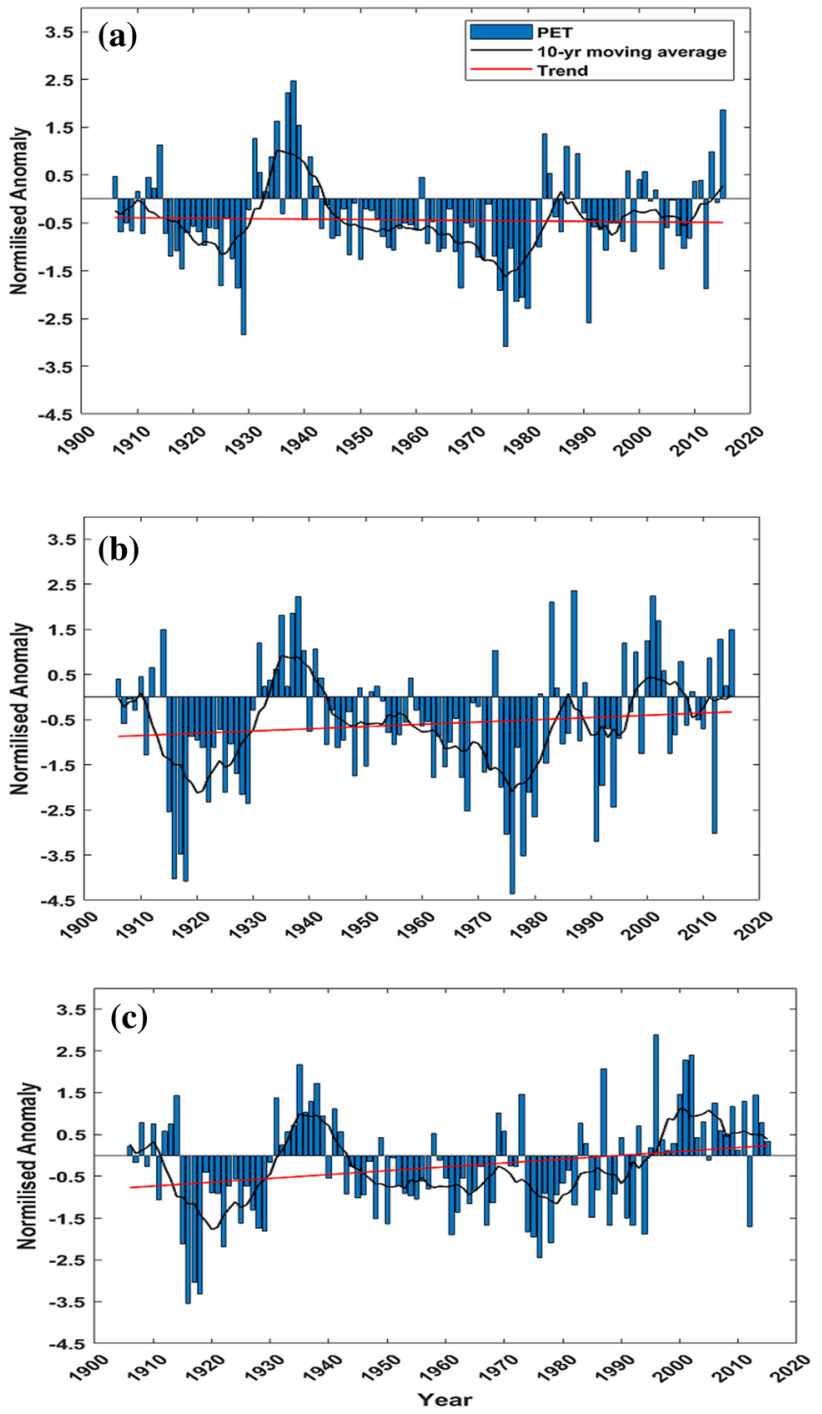

Fig. 5 Interannual variability in potential evapotranspiration from 1906 to 2015 in different zones of West Africa: a Guinea, b Savanna and c Sahel

zones, i.e. entire West Africa. Results of K-S test on the CDF curves suggested no significant difference in PET between these periods. Furthermore, precipitation decreased over the entire region between 1931-1960 and 1961-1990 with a significant increase of $115.5 \mathrm{~mm}$ or $15.23 \%$ over Sahel (Table 1). During this period, the observed percentage increase in cloud cover (0.01-0.05\%), decrease in vapour pressure $(0.02-0.33 \%)$ and temperatures $(0.13-1.07 \%)$ were found to be insignificant.

\subsection{Impacts of meteorological variables on PET variations}

Table 3 shows the results of the nonparametric regression analysis and correlation between PET and selected 


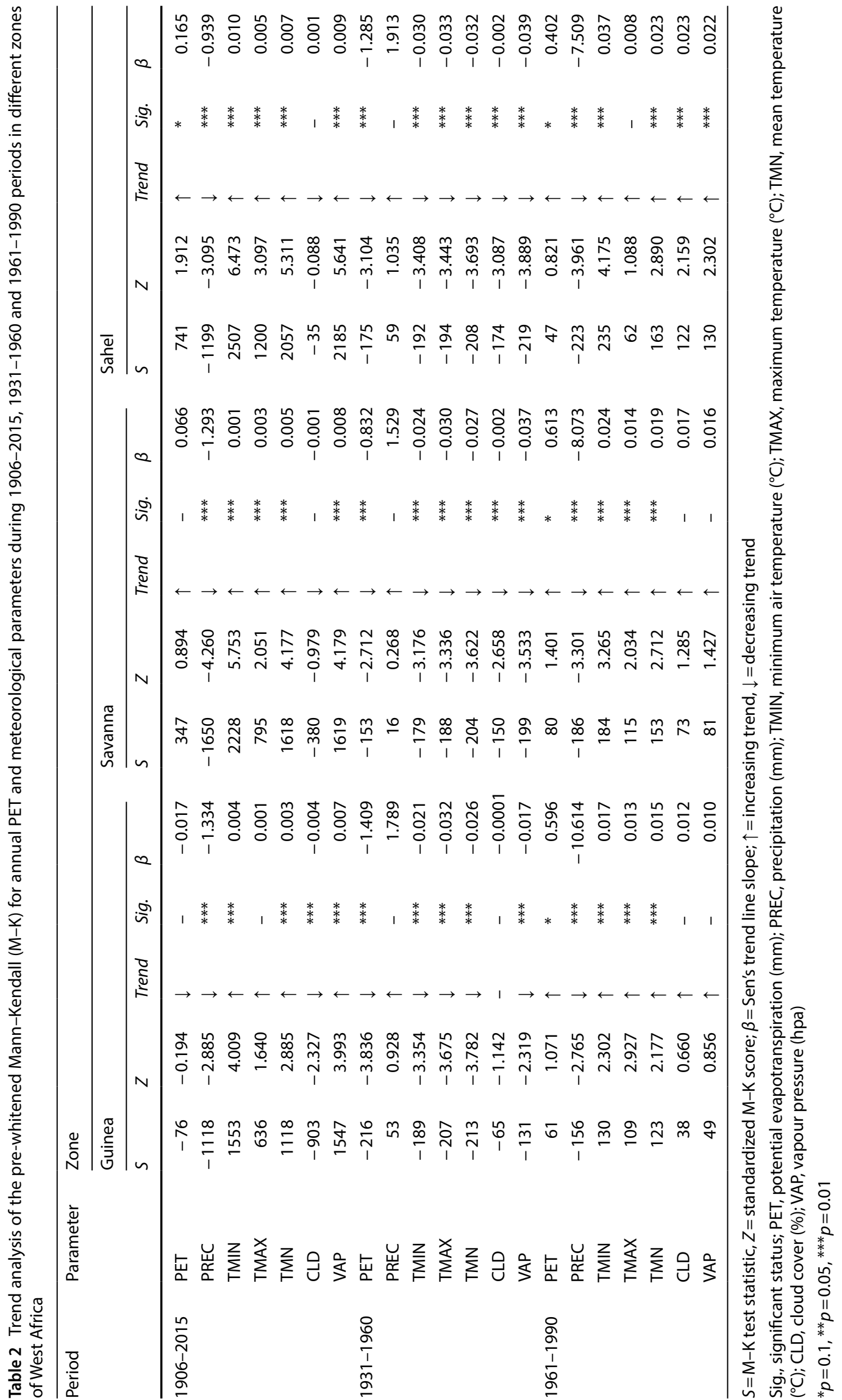


Fig. 6 Interannual variability in potential evapotranspiration for 1931-1960 and 1961-1990 reference periods in different zones of West Africa: $\mathbf{a}, \mathbf{b}$ Guinea, c, d Savanna and $\mathbf{e}, \mathbf{f}$ Sahel
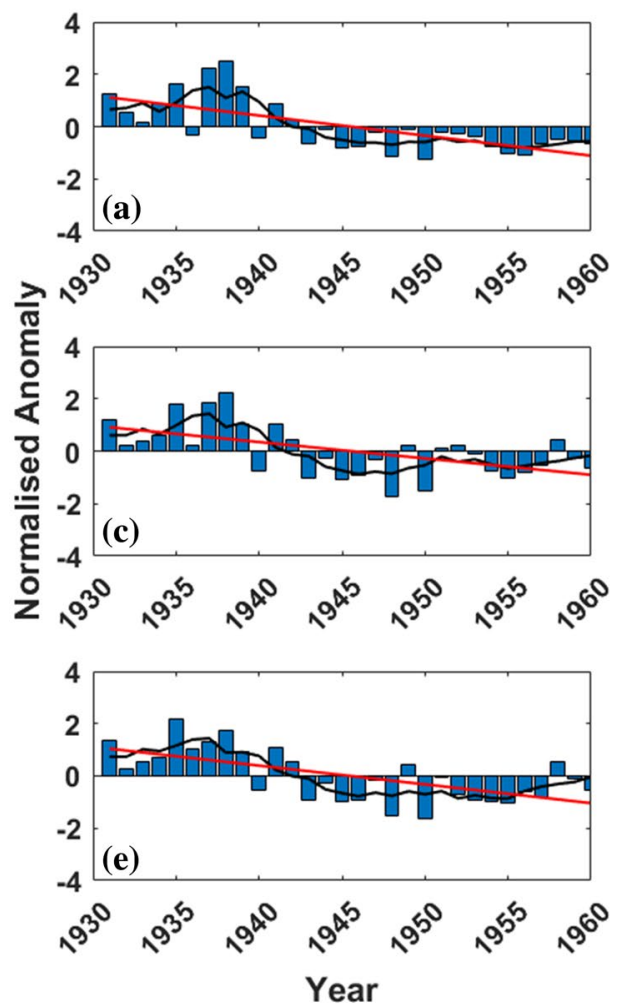
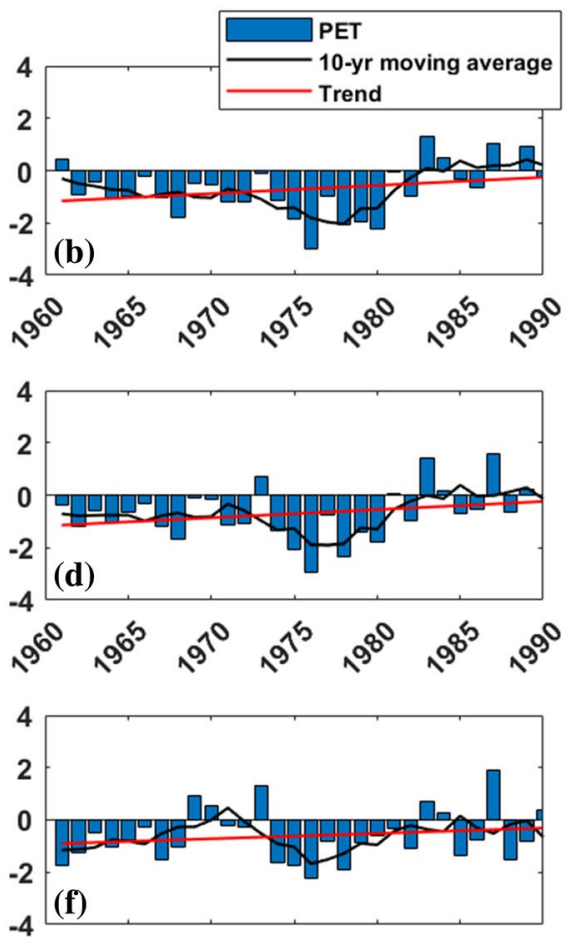

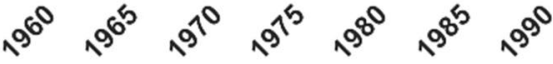
Year
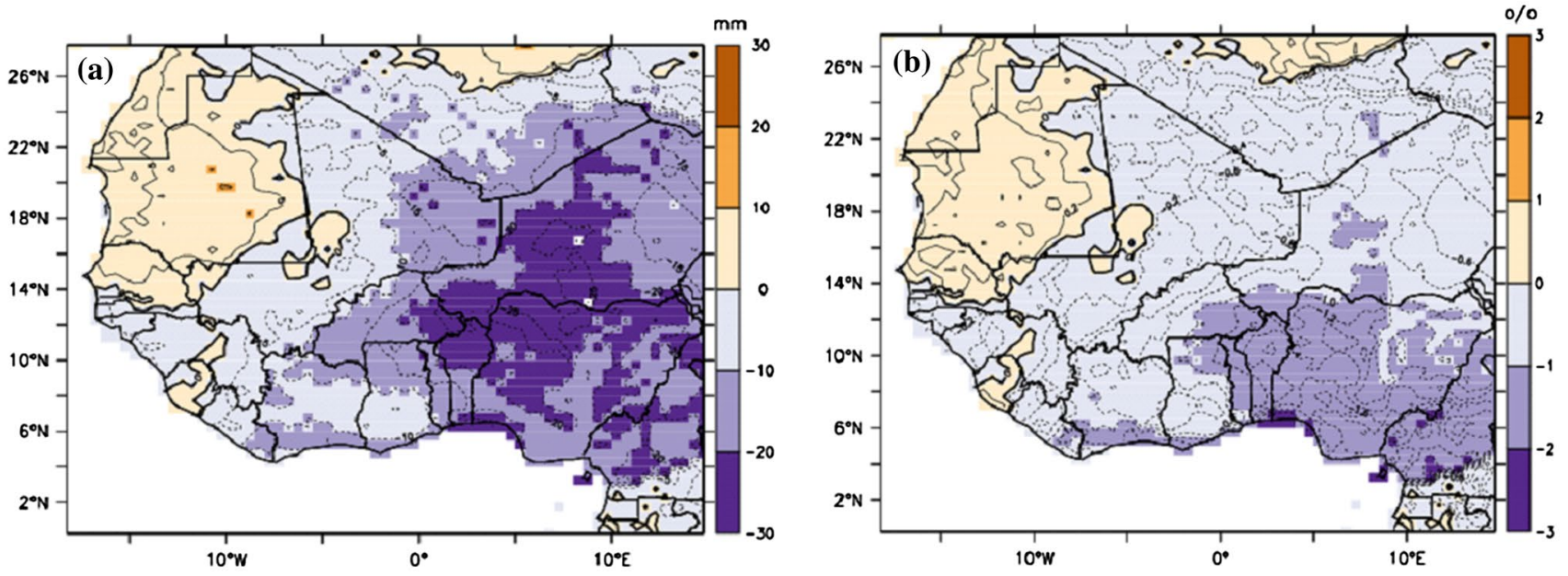

Fig. 7 Change in annual potential evapotranspiration between 1931-1960 and 1961-1990 reference periods: a change (mm year ${ }^{-1}$ ) and b percentage change (\%)

meteorological variables. Specifically, the results describe the patterns and contributions of changes in precipitation, temperatures, cloud cover and vapour pressure to the variation in PET over West Africa during the study periods. Correlation coefficients $(r$ ) obtained between temperatures (minimum, maximum and mean) and PET were found to be positive, significant at $a=0.01$ and ranged from 0.477 to 0.993 at different periods of study and in all zones (Table 3 ). In addition, the $r$ values generally increased from Guinea in the coast to Sahel in the interior north. Vapour pressure also showed positive correlation with PET. Of interest are the significant $r$ values $(0.621 \leq r \leq 0.770$ at $p=0.01)$ obtained between vapour pressure and PET during 1931-1960 period over the entire West Africa. On the other hand, significant negative $r$ values $(-0.268 \leq r \leq-0.565$ at $p=0.01)$ were 


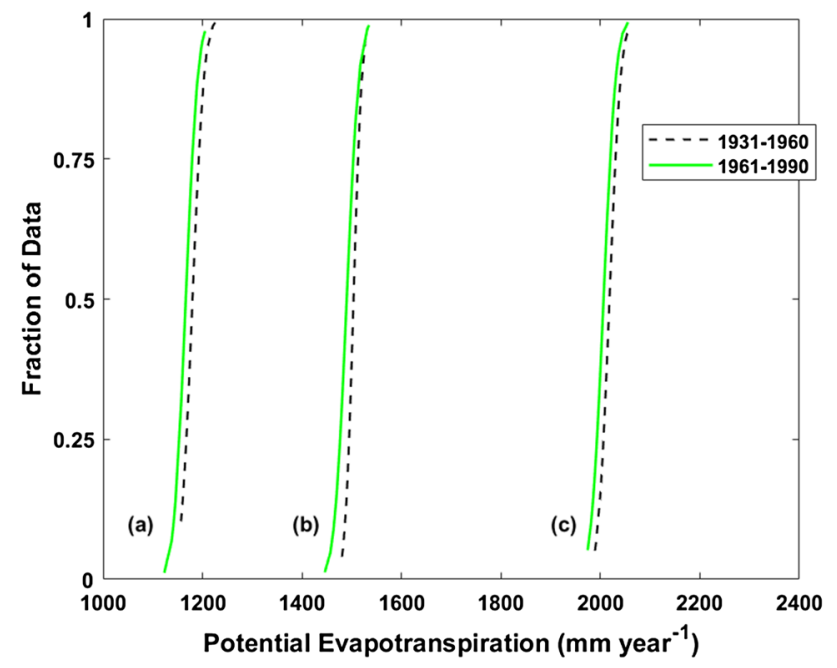

Fig. 8 Cumulative distribution function (CDF) curves of spatial potential evapotranspiration for 1931-1960 and 1961-1990 reference periods in different zones of West Africa: a Guinea, b Savanna and c Sahel zones

obtained between precipitation and PET particularly in Savanna and Sahel during 1961-1990 and the entire study period, i.e. 1906-2015. Similarly, cloud cover was negatively correlated with PET (significant at $a=0.01$ ) in virtually all periods and zones. The Theil and Sen's slope of regression $(\beta)$ values obtained varied across the zones and periods of study (Table 3 ). At different time periods, the highest values of $\beta$ were obtained for maximum temperatures ranging between 23.5 and $50.25 \%$. Contributions of cloud cover, represented by $\beta$ values, were significant at $\alpha=0.01$ and ranged between $-12.70 \%$ and -18.25 over all zones during 1961-1990 period. Similarly, range of $\beta$ values with vapour pressure was $16.72-27.05 \%$ across all zones during 1931-1960 and just $18.42 \%$ over Sahel zone during 1961-1990 period. However, $\beta$ values obtained with precipitation were $\ll-1 \%$ and insignificant over all zones and periods.

\section{Discussion}

Results revealed that annual mean PET increased from about $1000 \mathrm{~mm}$ in the coastline, southern West Africa, to about $2400 \mathrm{~mm}$ in the interior north. In addition, the least PET values were recorded in the coastline Guinea zone, which had the highest annual mean precipitation
Table 3 Results of nonparametric Theil and Sen's slope regression and correlation analyses of annual time series of potential evapotranspiration with some selected meteorological parameters during 1906-2015, 1931-1960 and 1961-1990 special periods in different zones of West Africa

\begin{tabular}{|c|c|c|c|c|c|c|c|}
\hline \multirow[t]{3}{*}{ Period } & \multirow[t]{3}{*}{ Parameter } & \multicolumn{6}{|l|}{ Zone } \\
\hline & & \multicolumn{2}{|l|}{ Guinea } & \multicolumn{2}{|l|}{ Savanna } & \multicolumn{2}{|l|}{ Sahel } \\
\hline & & $\beta(\%)$ & $r$ & $\beta(\%)$ & $r$ & $\beta(\%)$ & $r$ \\
\hline \multirow[t]{6}{*}{ 1906-2015 } & PREC & -0.010 & -0.143 & - & $-0.268^{* * *}$ & -0.076 & $-0.303^{* * *}$ \\
\hline & TMIN & - & $0.566^{* * *}$ & $22.531^{* * * *}$ & $0.502^{* * *}$ & $26.158^{* * *}$ & $0.572^{* * *}$ \\
\hline & TMAX & $39.231^{* * *}$ & $0.853^{* * *}$ & - & $0.841^{* * *}$ & $28.67^{* * *}$ & $0.905^{* * *}$ \\
\hline & TMN & - & $0.477^{* * *}$ & $35.500^{* * *}$ & $0.720^{* * *}$ & - & $0.785^{* * *}$ \\
\hline & CLD & - & $-0.537^{* * *}$ & - & $-0.477^{* * *}$ & - & $-0.371^{* * *}$ \\
\hline & VAP & - & $0.254^{* * *}$ & 9.195 & $0.199 * * *$ & - & $0.549^{* * *}$ \\
\hline \multirow[t]{6}{*}{ 1931-1960 } & PREC & 0.012 & 0.127 & 0.008 & 0.032 & -0.076 & -0.273 \\
\hline & TMIN & $35.165^{* * *}$ & $0.789^{* * *}$ & $21.397^{* * *}$ & $0.657^{* * *}$ & $27.855^{* * *}$ & $0.685^{* * *}$ \\
\hline & TMAX & $34.890^{* * *}$ & $0.954^{* * *}$ & $31.885^{* * *}$ & $0.965^{* * *}$ & $41.063^{* * *}$ & $0.993^{* * * *}$ \\
\hline & TMN & $39.542^{* * *}$ & $0.919^{* * *}$ & $31.713^{* * *}$ & $0.878^{* * * *}$ & $39.922^{* * *}$ & $0.893^{* * *}$ \\
\hline & CLD & - & 0.231 & - & $0.382^{* *}$ & - & $0.431^{* *}$ \\
\hline & VAP & $22.000^{* * *}$ & $0.621^{* * * *}$ & $16.718^{* *}$ & $0.687^{* * *}$ & $27.053^{* *}$ & $0.770^{* * * *}$ \\
\hline \multirow[t]{6}{*}{ 1961-1990 } & PREC & -0.029 & -0.285 & -0.100 & $-0.469^{* * *}$ & -0.132 & $-0.565^{* * *}$ \\
\hline & TMIN & $29.200^{* * *}$ & $0.603^{* * *}$ & $30.601^{* * *}$ & $0.595^{* * *}$ & $24.333^{* *}$ & $0.515^{* * *}$ \\
\hline & TMAX & $45.402^{* * *}$ & $0.871^{* * *}$ & $50.247^{* * *}$ & $0.890^{* * *}$ & $47.450^{* * *}$ & $0.933^{* * *}$ \\
\hline & TMN & $40.044^{* * *}$ & $0.762^{* * *}$ & $44.435^{* * *}$ & $0.782^{* * *}$ & $43.234^{* * *}$ & $0.796^{* * * *}$ \\
\hline & CLD & $-18.025^{* *}$ & $-0.628^{* * * *}$ & $-18.250^{* *}$ & $-0.606^{* * *}$ & $-12.696^{* *}$ & $-0.473^{* * *}$ \\
\hline & VAP & 8.588 & 0.169 & 0.794 & 0.027 & $18.417^{* *}$ & $0.448^{* *}$ \\
\hline
\end{tabular}

$\beta=$ nonparametric Theil and Sen's slope of regression and $r=$ correlation coefficient

Sig., significant status; PREC, precipitation ( $\mathrm{mm})$; TMIN, minimum air temperature $\left({ }^{\circ} \mathrm{C}\right) ; \mathrm{TMAX}$, maximum temperature $\left({ }^{\circ} \mathrm{C}\right) ; \mathrm{TMN}$, mean temperature $\left({ }^{\circ} \mathrm{C}\right) ; \mathrm{CLD}$, cloud cover $(\%)$; VAP, vapour pressure (hpa)

${ }^{*} p=0.1,{ }^{* *} p=0.05,{ }^{* * *} p=0.01$ 
(1784 $\mathrm{mm})$, cloud cover (80\%) and vapour pressure (25.8 hpa) but lowest mean temperature $\left(26^{\circ} \mathrm{C}\right)$. Remarkable general increase in the values of PET inland from the coast is probably a reflection of the rapid change in cloudiness between areas to the north and south $[3,8]$. Hence, the smallest PET values along the coastlands are a reflection of greater development of cloudiness in the zone that reduces the incoming solar radiation with a consequent reflection in the small amount of net radiation available for PET. Observed non-uniformity of spatial pattern of distribution of PET within a given zone could be a reflection of the characteristics of the local conditions such as topography, vegetative cover, availability of soil moisture, reflective land surface, and change in land use/land cover $[9,10,70]$.

Furthermore, there were noticeable variations in monthly and seasonal PET over West Africa. The longterm climatology of PET indicated that the monthly mean values were higher in dry months than the wet. It suggested seven (7) months of water surplus, i.e. wet season (April-October) in Guinea, six (6) months (May-October) in Savanna and three (3) months (July-September) in Sahel. In other words, there were five (5) months of water deficit, i.e. dry season in Guinea, six (6) months in Savanna and nine (9) months in Sahel. This is so because according to Hayward and Oguntoyinbo [8], the location of Inter-Tropical Discontinuity (ITD) has significant impact on the seasonal changes in PET over West Africa. The months of water surplus coincided with crop cultivation period in the study area. This implies seven (7) months of cropping season in Guinea, six (6) months in Savanna and only three (3) months in Sahel. The relatively long period of water deficit in the Sahel has serious hydrological implications in the region-depending on other prevailing environmental conditions and human interventions [10]. Recent study in the south of Iran and the station Tehran reported that an increased aerosol loadings due to increase in anthropogenic air pollution as well as natural aerosols from dust storms could substantially reduce surface net radiation and increase cloud cover [11]. Thus, seasonal variations in PET could be modified (reduced) by Harmattan haze in sub-Saharan Africa, particularly during the dry season.

Results of the trend analysis of the PET showed mixed (positive and negative trends) results during different periods of study. Over the entire 110-year study period, annual mean PET was found to have increased by $18.5 \mathrm{~mm}(\sim 0.165 \mathrm{~mm}$ per year) in Sahel and $7.26 \mathrm{~mm}$ (0.066 $\mathrm{mm}$ per year) in Savanna but decreased by $1.87 \mathrm{~mm}(0.017 \mathrm{~mm}$ per year) in Guinea. The trend over Sahel was found to be significant at $p=0.1$. During this long-term period of increasing PET in Sahel, precipitation was found to be increasing significantly (at $p=0.05$ ) by about $0.94 \mathrm{~mm}$ per year. In addition, both temperatures and vapour pressure increased significantly (at $p=0.05$ ) across the zones. Observed increase in trends of temperature, vapour pressure and precipitation could have resulted in increasing trend in PET over Sahel zone $[14,40]$.

However, very sharp differences in PET were observed for both 1931-1960 and 1961-1990 WMO reference periods. The results revealed significant decreasing trends (at $p=0.01$ ) in PET during $1931-1960$ period but significant increasing trends (at $p=0.1$ ) during 1961-1990 over the entire West African region. This pattern of variations is in agreement with the findings of Dinpashoh et al. [27] in north-west Iran where most of the stations selected $(86 \%$ of the sites) also showed increasing trends in PET between 1997 and 2016.

In a similar manner, temperatures significantly decreased and increased during the 1931-1960 and 1961-1990 periods, respectively. Precipitation, however, showed increasing trends during the first period but decreasing significant trends during the second. The decrease and increase in PET during the two reference periods could be attributed to the impacts of (similar pattern of variation in the trends of) temperatures over the region, i.e. increase in air temperature induces increase in PET $[39,40]$. Some alternating periods of PET deficit and periods of PET excess, similar to the findings of this study, have also been reported over different locations in Benin, West Africa $[2,6]$.

Although results showed both negative and positive changes in PET during 1961-1990 period relative to $1931-1960$, general reductions in PET $(-11.95 \mathrm{~mm}$ to $-13.74 \mathrm{~mm}$ or $-0.6 \%$ to $-1.2 \%$ ) were observed in the entire West African region. The upward shift in 1961-1990 CDF curves relative to those of 1931-1960 in all the designated zones also suggested decrease in PET in the entire region. However, these changes in PET were found to be insignificant. Reductions in PET during these two reference periods could be attributed to decrease in temperature (0.13-1.07\%), precipitation (4.29-15.23\%) and vapour pressure $(0.02-0.33 \%)$.

Any changes in meteorological variables due to climate change have been reported to modify PET [13]. The findings of the present study suggested significant strong positive correlation between temperatures (minimum, maximum and mean) and PET at different periods of study and in all zones. This supports a decrease and increase in PET and temperature obtained during the two reference periods, respectively. Thus, keeping all other variables constant, projected future warmer climate by different climate models as reported in Abiodun et al. [47] is expected to produce rise in PET over most regions in West Africa. Because $r$ values were higher over Sahel than the coastline 
area, the impacts of future warming (climate change) on PET are suggested to be higher in the Sahel. Furthermore, significant negative correlation obtained between cloudiness and PET is an indication of increased PET over Sahel region under future decrease in cloudiness. However, contribution of increased anthropogenic air pollution and aerosol loadings to reduction in surface net radiation and increment in cloud cover could reduce PET over the region as suggested by Jahani et al. [11].

Finally, temperature (maximum, minimum and mean) was found to be the key contributor to the observed variations in PET in the study area during different time periods. During 1931-1960 period, observed decreasing trend in maximum temperature substantially contributed $34.9 \%, 31.9 \%$ and $41.1 \%$ to the reduction in PET in Guinea, Savanna and Sahel zones, respectively. The contributions of vapour pressure were also significant at 0.01 and ranged between 16.7 and $27.1 \%$ over all zones. During 1961-1990 period, however, an observed increasing trend in maximum temperature substantially contributed $45.4 \%, 50.2 \%$ and $47.5 \%$ to the increment in PET in Guinea, Savanna and Sahel zones, respectively. Contributions of cloud cover were significant at 0.01 and ranged between $-12.70 \%$ and - 18.25 over all zones, while vapour pressure accounted for $18.42 \%$ variations in PET over Sahel zone. However, contribution of precipitation to variations in PET was found to be negligible over all zones and periods. This is in agreement with the findings of Xu et al. [19], Chattopadhyay and Hulme [1] and Tang et al. [42].

\section{Conclusion}

This study has investigated changes and trends of longterm series (1906-2015) of observed potential evapotranspiration (PET) over West Africa. It also assessed changes in PET for the 1931-1960 and 1961-1990 World Meteorological Organization (WMO) reference periods and quantified the contributions of some key meteorological parameters to the variations in PET. Monthly time series of the Global Gridded Climatology data (version TS 4.00) obtained from the Climate Impacts LINK project, Climate Research Unit (CRU), University of East Anglia, Norwich, UK, were used. Results revealed that mean PET increased from the coastline to the interior north, a reflection of latitudinal variation in cloudiness, land use/land cover and other characteristics of the local conditions. There were marked variations in monthly mean PET over the entire region, higher in dry months than in the wet. The reason was traceable to a strong link between PET and the seasonal movement of the Inter-Tropical Discontinuity (ITD). Results of the trend analysis of the PET showed mixed (positive and negative trends) results during different periods of study. It suggested significant increasing trends in annual mean PET in Sahel but decrease in Savanna and Guinea. This was attributed to increase in observed temperature, vapour pressure and precipitation over the zone. However, very sharp differences in PET were observed for both 1931-1960 and 1961-1990 periods. It revealed significant decreasing trends (at $p \leq 0.01$ ) in PET during 1931-1960 period but significant increasing trends (at $p=0.1$ ) during 1961-1990 over the entire West African region. Although results showed both negative and positive changes in PET between the two reference periods, general reductions in PET were observed in the entire region due to decrease in temperature and vapour pressure as well as increase in cloud cover. Finally, temperature (maximum, minimum and mean) was found to be the most significant contributor to the observed variations in PET.

\section{Compliance with ethical standards}

Conflict of interest The authors declare that they have no competing interests.

\section{References}

1. Chattopdhyay N, Hulme M (1997) Evaporation and potential evapotranspiration in India under conditions of recent and future climate change. Agric For Meteorol 87:55-73

2. Hounnou FE, Dedehouanou H (2018) Variability of temperature, precipitation and potential evapotranspiration time series analysis in republic of Benin. Int J Agric Environ Res 4(4):991-1019

3. Ojo O (1969) Potential evapotranspiration and the water balance in West Africa. Theor Appl Climatol 17(2):239-260. https://doi. org/10.1007/BF02243168

4. Granger RJ (1989) An examination of the concept of potential evaporation. J Hydrol 111(1-4):9-19

5. Lhomme JP (1999) Towards a rational definition of potential evaporation. Hydrol Earth Syst Sci 1(2):257-264

6. Obada E, Alamou EA, Chabi A, Zandagba J, Afouda A (2017) Trends and changes in recent and future Penman-Monteith potential evapotranspiration in Benin (West Africa). Hydrol 4:38. https://doi.org/10.3390/hydrology 4030038

7. Edoga RN (2007) Determination of length of growing season in Samaru using different potential evapotranspiration models. AUJT 11(1):28-35

8. Hayward DF, Oguntoyinbo JS (1987) Climatology of West Africa, 6th edn. Hutchinson, London

9. Li Y, Feng A, Liu W, Ma X, Dong G (2017) Variation of aridity index and the role of climate variables in the southwest China. Water 9:743. https://doi.org/10.3390/w9100743

10. Ashaolu ED, Iroye KA (2018) Rainfall and potential evapotranspiration patterns and their effects on climatic water balance in the Western Lithoral Hydrological Zone of Nigeria. Ruhuna J Sci 9(2):92-116. https://doi.org/10.4038/rjs.v9i2.45

11. Jahani B, Dinpashoh $Y$, Wild M (2018) Dimming in Iran since the 2000s and the underlying causes. Int J Climatol 38:1543-1550 
12. Dinpashoh $Y$, Jhajharia D, Fakheri-Fard A, Singh VP, Kahya E (2011) Trends in reference crop evapotranspiration over Iran. J Hydrol 399:422-433

13. Zhang YF, Deng JL, Guan DX, Jin CJ, Wang AZ, Wu JB, Yuan FH (2011) Spatiotemporal changes of potential evapotranspiration in Songnen plain of Northeast China. Chin J Appl Ecol 22:1702-1710

14. Jhajharia D, Pandey PK, Dabral PP, Kumar R, Choudhary R (2015) Variability in temperature and potential evapotranspiration over West Siang in Arunachal Pradesh. J Ind Geil Congr 7:37-43

15. Liu Q, Yan C, Ju H, Garré S (2017) Impact of climate change on potential evapotranspiration under a historical and future climate scenario in the Huang-Huai-Hai Plain, China. Theor Appl Climatol 132:387-401. https://doi.org/10.1007/s0070 4-017-2060-6

16. Li Z, Zheng F, Liu W (2012) Spatiotemporal characteristics of reference evapotranspiration during 1961-2009 and its projected changes during 2011-2099 on the Loess Plateau of China. Agric For Meteorol 154-155:147-155

17. Fan ZX, Thomas A (2013) Spatiotemporal variability of reference evapotranspiration and its contributing climatic factors in Yunan Province, SW China, 1961-2004. Clim Change 116:309-325

18. Alemu H, Senay GB, Kaptue AT, Kovalskyy V (2014) Evapotranspiration variability and its association with vegetation dynamics in the Nile Basin, 2002-2011. Remote Sens 6:5885-5908. https ://doi.org/10.3390/rs6075885

19. Xu YP, Pan S, Fu G, Tian Y, Zhang X (2014) Future potential evapotranspiration changes and contribution analysis in Zhejiang Province, East China. J Geophys Res Atmos 118:2174-2192

20. Labat D, Goddéris Y, Probst JL, Guyot JL (2004) Evidence for global runoff increase related to climate warming. Adv Water Res 27:631-642

21. Huntington TG (2006) Evidence for intensification of the global water cycle: review and synthesis. J Hydrol 319:83-95

22. Gao G, Chen D, Xu CY, Simelton E (2007) Trend of estimated actual evapotranspiration over China during 1960-2002. J Geophys Res 112:11

23. Chaouche K, Neppel L, Dieulin C, Pujol N, Ladouche B, Martin E, Salas D, Caballero Y (2010) Analyses of precipitation, temperature and evapotranspiration in a French Mediterranean region in the context of climate change. C R Geosci 342(3):234-243

24. Kousari MR, Asadi Zarch MA, Ahani H, Hakimelahi H (2013) A survey of temporal and spatial reference crop evapotranspiration trends in Iran from 1960 to 2005. Clim Change 120:277-298

25. Tabari H, Grismer ME, Trajkovic S (2013) Comparative analysis of 31 reference evapotranspiration methods under humid conditions. Irrig Sci 31:107-117. https://doi.org/10.1007/s0027 1-011-0295-z

26. Talaee HP, Somee'e SB, Ardakani SS (2013) Time trend and change point of reference evapotranspiration over Iran. Theor Appl Climatol. https://doi.org/10.1007/s00704-013-0978-x

27. Dinpashoh Y, Jahanbakhsh-AsI S, Rasouli AA, Foroughi M, Singh VP (2019) Impact of climate change on potential evapotranspiration (case study: west and NW of Iran). Theor Appl Climatol 136(1-2):185-201

28. Onyutha C (2016) Statistical analyses of potential evapotranspiration changes over the period 1930-2012 in the Nile River riparian countries. Agric For Meteorol 226-227:80-95

29. Darshana D, Pandey A, Pandey RP (2013) Analysing trends in reference evapotranspiration and weather variables in the Tons River Basin in Central India. Stoch Environ Res Risk Assess 27:1407-1421. https://doi.org/10.1007/s00477-012-0677-7
30. Chen SB, Lui YF, Thomas A (2006) Climatic change on the Tibetan Plateau: potential evapotranspiration trends from 1961-2000. Clim Change 76:291-319

31. Yin Y, Wu S, Chen G, Dai E (2010) Attribution analyses of potential evapotranspiration changes in China since the 1960s. Theor Appl Climatol 101:19-28. https://doi.org/10.1007/s0070 4-009-0197-7

32. Irmak S, Kabenge I, Skaggs KE, Mutiibwa D (2012) Trend and magnitude of changes in climate variables and reference evapotranspiration over 116-year period in the Platte River Basin, central Nebraska-USA.J Hydrol 420-421:228-244

33. Goyal R (2004) Sensitivity of evapotranspiration to global warming: a case study of arid zone of Rajasthan (India). Agric Water Manag 69(1):1-11

34. Thomas A (2000) Spatial and temporal characteristics of potential evapotranspiration trends over China. Int J Climatol 20:381-396

35. Wang YJ, Jiang T, Bothe O, Fraedrich K (2007) Changes of pan evaporation and reference evapotranspiration in the Yangtze River basin. Theor Appl Climatol 90(1-2):13-23

36. Song F, Zhou T, Qian Y (2014) Responses of East Asian summer monsoon to natural and anthropogenic forcings in the 17 latest CMIP5 models. Geophys Res Lett 41:596-603. https://doi. org/10.1002/2013GL058705

37. Suat I, Kabenge I, Skaggs KE, Mutiibwa D (2012) Trend and magnitude of changes in climate variables and reference evapotranspiration over 116-yr period in the Platte River Basin, central Nebraska-USA. Hydrol 420-421:228-244. https ://doi.org/10.1016/j.jhydrol.2011.12.006

38. Gao G, Chen D, Ren G, Chen Y, Liao Y (2006) Spatial and temporal variations and controlling factors of potential evapotranspiration in China: 1956-2000. J Geogr Sci 16(1):3-12

39. Tabari H, Marofi S, Hosseinzadehtalaei AA, Mohammadi $P$ (2011) Trend analysis of reference evapotranspiration in the western half of Iran. Agric For Meteorol 151:128-136

40. Liu H, Li Y, Josef T, Zhang R, Huang G (2014) Quantitative estimation of climate change effects on potential evapotranspiration in Beijing during 1951-2010. J Geogr Sci 24(1):93-112. https://doi.org/10.1007/s11442-014-1075-5

41. Sharifi A, Dinpashoh Y (2014) Sensitivity analysis of the Penman-Monteith reference crop evapotranspiration to climatic variables in Iran. Water Resour Manage 28:5465-5476. https ://doi.org/10.1007/s11269-014-0813-x

42. Tang B, Tong L, Kang SZ, Zhang L (2011) Impacts of climate variability on reference evapotranspiration over 58 years in the Haihe River Basin of North China. Agric Water Manag 98:1660-1670

43. Liu C, Zhang D, Liu X, Zhao C (2012) Spatial and temporal change in the potential evapotranspiration sensitivity to meteorological factors in China (1960 - 2007). J Geogr Sci 22(1):3-14

44. Rind D, Goldberg R, Hansen J, Rosenzweig C, Ruedy R (1990) Potential evapotranspiration and the Likelihood of future drought. J Geophys Res 95(D7):9983-10004

45. Valipour M (2014) Study of different climatic conditions to assess the role of solar radiation in reference crop evapotranspiration equations. Arch Agron Soil Sci 61:679-694

46. Omotosho JB, Abiodun BJ (2007) A numerical study of moisture build-up and rainfall over West Africa. Meteorol Appl $14: 209-225$

47. Abiodun BJ, Adeyewa ZD, Oguntunde PG, Salami AT, Ajayi VO (2012) Modelling the impacts of reforestation on future climate in West Africa. Theor Appl Climatol 110:77-96. https:// doi.org/10.1007/s00704-012-0614-1

48. Harris IC, Jones PD, Osborn TJ, Lister DH (2014) Updated highresolution grids of monthly climatic observations-the CRU TS4.00 dataset. Int J Climatol 34:623-642 
49. Mitchell TD, Hulme M, New M (2001) Climate data for political areas. Observations 109:112

50. Mitchell TD, Jones PD (2005) An improved method of constructing a database of monthly climate observations and associated high-resolution grids. Int J Climatol 25:693-712

51. Salmi T, Maatta A, Anttila P, Ruoho-Airola T, Amnell T (2002) Detecting trends of annual values of atmospheric pollutants by the Mann-Kendall Test and Sen's slope estimates. Publications on Air Quality, No. 31. Helsinki, Finland

52. Tosic I, Unkasevic M (2005) Analysis of precipitation series for Belgrade. Theor Appl Climatol 80(1):67-77

53. Oguntunde PG, Friesen J, van de Giesen N, Savenije HHG (2006) Hydroclimatology of the Volta River Basin in West Africa: trends and variability from 1901 to 2002. Phys Chem Earth 31:1180-1188

54. Oguntunde PG, Abiodun BJ, Lischeid G (2011) Rainfall trends in Nigeria, 1901-2000. Hydrol 411:207-218

55. Hulme M (1992) Rainfall changes in Africa: 1931-1960 to 19611990. Int J Climatol 12:685-699

56. Cannarozzo M, Noto LV, Viola $F$ (2006) Spatial distribution of rainfall trends in Sicily (1921-2000). Phys Chem Earth 31:1201-1211

57. Kahya E, Kalaycı S (2004) Trend analysis of stream flow in Turkey. J Hydrol 289:128-144

58. Jhajharia D, Dinpashoh $Y$, Kahya E, Singh VP, Fakheri-Fard A (2011) Trends in reference evapotranspiration in the humid region of northeast India. Hydrol Process. https://doi. org/10.1002/hyp.8140

59. Mann HB (1945) Non-parametric tests against trend. Econometrica 33:245-259

60. Kendall MG (1975) Rank correlation methods, 4th edn. Charles Griffin, London

61. Yue S, Pilon P, Phinney B, Cavadias G (2002) The influence of autocorrelation on the ability to detect trend in hydrological series. Hydrol Process 16:1807-1829

62. Theil H (1950) A rank invariant method of linear and polynomial regression analysis, Part 3. Netherlands Akademie van Wettenschappen, Proc 53:1397-1412
63. Sen PK (1968) Estimates of the regression coefficient based on Kendall's Tau. J Am Stat Assoc 63:1379-1389

64. Wang W, Chen X, Shi P, van Gelder PHAJM (2008) Detecting changes in extreme precipitation and extreme stream flow in the Dongjiang River Basin in southern China. Hydrol Earth Syst Sci 12:207-221

65. Kim PJ (1969) On the exact and approximate sampling distribution of the two sample Kolmogorov-Smirnov criterion Dmn, m $\leq \mathrm{n}$. J Am Stat Assoc 64(328):1625-1637. https://doi. org/10.1080/01621459.1969.10501082

66. Lehmann EL (2006) Nonparametrics: statistical methods based on ranks. With the special assistance of D'Abrera HJ. Springer, New York, p 463

67. Greenwella RN, Finchb SJ (2004) Randomized rejection procedure for the two-sample Kolmogorov-Smirnov statistic. Comput Stat Data Anal 46:257-267

68. Kim PJ, Jennrich RI (1970) Tables of the exact sampling distribution of the kolmogorov-smirnov criterion. In: Harter HL, Owens DB (eds) Selected tables in mathematical statistics I. Markham, Chicago

69. Egwuonwu CC, Okafor VC, Ezeanya NC, Nzediegwu C, Okorafor OO (2012) A comparison of the reliability of six evapotranspiration computing models for Abeokuta in south western Nigeria. Greener J Phys Sci 2(4):64-69

70. Rim C-S (2009) The effects of urbanization, geographical and topographical conditions on reference evapotranspiration. Clim Change 97:483-514

Publisher's Note Springer Nature remains neutral with regard to jurisdictional claims in published maps and institutional affiliations. 